\title{
Níveis de Óleo e Adição de Complexo Enzimático na Ração de Frangos de Corte ${ }^{1}$ \\ Luiz Eduardo Avelar Pucci², Paulo Borges Rodrigues ${ }^{3}$, Rilke Tadeu Fonseca de Freitas ${ }^{3}$, Antonio Gilberto Bertechini ${ }^{3}$, Ezequiel Malfitano Carvalho ${ }^{4}$
}

\begin{abstract}
RESUMO - Dois experimentos foram conduzidos para avaliar o efeito da adição de óleo de soja e de um complexo enzimático em rações à base de milho e farelo de soja, sobre o desempenho de frangos de corte e a digestibilidade dos nutrientes. No experimento 1 , foram utilizados 960 pintos de corte, não sexados, os quais receberam os tratamentos em esquema fatorial 4 x 2 (quatro níveis de inclusão de óleo de soja: 0; 2,5; 5,0 e 7,5\%, com ou sem adição de um complexo enzimático contendo amilase, xilanase e protease), em quatro repetições de 30 aves cada, no período de 1 a 21 dias de idade. Dos 22 aos 42 dias de idade, todas as aves receberam uma mesma ração de crescimento, para avaliação de possível efeito residual dos tratamentos aplicados na fase inicial de criação sobre a fase seguinte. Aos 21 dias de idade, 90 aves (três machos e duas fêmeas de cada unidade experimental) foram transferidas para uma sala de metabolismo (experimento 2), em que as aves receberam as mesmas rações experimentais, para determinação dos valores energéticos e dos coeficientes de digestibilidade da matéria seca e do extrato etéreo. Não houve efeito da adição do complexo enzimático, nem interação dos níveis de óleo e suplementação com enzimas sobre o desempenho das aves. O valor energético das rações melhorou em 2,3\% com a adição de óleo, não havendo efeito da adição de enzimas. O nível de $2,33 \%$ de óleo permitiu máxima digestibilidade do extrato etéreo. Concluiu-se que a inclusão de óleo na ração melhorou o desempenho das aves e a conversão alimentar permaneceu constante a partir de 2,18\% de inclusão.
\end{abstract}

Palavras-chave: desempenho, digestibilidade, energia metabolizável, enzimas

\section{Oil Levels and Enzymatic Complex Addition in Broiler Diets}

\begin{abstract}
S - Two experimental assays were carried out to evaluate the effect of the soybean oil and enzymatic complex addition in corn and soybean meal based diets on the broilers performance and nutrients digestibility. In the experiment 1, 960 broiler chickens, unsexed, received the treatments into $4 \times 2$ factorial scheme (four levels of soybean oil addition, $0 ; 2.5 ; 5.0$ and $7.5 \%$, with or without addition of a enzymatic complex with amylase, xylanase and protease) in four replicates of 30 chickens each, from 1 to 21 days of age. After the first phase, the broilers fed a standard diet until 42 days of age to evaluate a possible residual effect of the treatments on the performance from 22 to 42 days old. At the 21 days of age, 90 chickens (three male and two female of each replicate) were transfered to metabolism room (experiment 2), were the chickens received the same experimental diets to determination of the energetic values and dry matter and ether extract digestibility coefficients. The results shown no effect of the enzymatic complex addition nor interaction of the oil levels and enzyme supplementation on the broilers performance. The energetic value of the diets enhanced in $2.3 \%$ with the oil addition, without enzyme supplementation effect. The oil level of the $2.33 \%$ allowed a maximum digestibility of the ether extract. It was concluded that oil addition in the diet result in a better broilers performance and feed conversion reached the plateau in the $2.18 \%$ oil level.
\end{abstract}

Key Words: broilers performance, digestibility, enzymes, metabolizable energy

\section{Introdução}

Apesar das constantes pesquisas sobre o uso de alimentos não convencionais em rações de aves, as formulações ainda são basicamente com milho e farelo de soja, principais fontes protéica e energética. No entanto, para melhor balanceamento energético, é necessária a inclusão de óleo vegetal e/ou gordura nas rações. O National Research Council (NRC, 1994) destaca a melhora na palatabilidade e na conversão alimentar e a redução na perda de nutrientes, entre outros, como efeitos benéficos do uso de gorduras nas formulações. Tais efeitos são comumente denominados de "efeito extra-calórico". De acordo com Franco (1992), o efeito extra-calórico da gordura refere-se à maior energia líquida desta, uma vez que a deposição de gordura na ave é muito mais eficiente quando se utiliza a gordura dietética do que a síntese de ácidos graxos e glicerol a partir de precursores da acetil coenzima A. Dessa forma, quando a gordura é incluída na dieta, ocorre redução da síntese de ácidos graxos e a ave dispõe de mais energia para os propósitos produtivos que se propõe. O efeito da gordura em aumentar o tempo de trânsito da digesta também foi

\footnotetext{
${ }^{1}$ Parte da dissertação de mestrado do primeiro autor.

2 Zootecnista, Mestre em Nutrição de Monogástricos. E.mail: leapucci@ufac.br

${ }^{3}$ Professores do Departamento de Zootecnia da UFLA. E.mail: pborges@ufla.br

${ }^{4}$ Zootecnista, Aluno de Pós-Graduação do DZO/UFLA. E.mail: cfc@ufla.br
} 
destacado como resposta para o seu efeito extracalórico (Mateos \& Sell, 1981). Porém, em trabalhos conduzidos por Andreotti et al. (1999), observou-se redução no tempo de trânsito a medida que incluíram óleo na ração.

$\mathrm{Na}$ década de 70, Teixeira (1974) avaliou a utilização de vários níveis de inclusão do óleo de soja na ração de frangos de corte, observando ganho de peso máximo das aves nos níveis de 7,04 e 8,66 \% de inclusão, respectivamente para as fases inicial e final. Mais recentemente, trabalhando com frangos de corte no período de um a 21 dias de idade, Freitas et al. (1999a,b) mostraram melhora no desempenho e na digestibilidade do extrato etéreo, quando o óleo de soja foi adicionado na ração.

Por outro lado, apesar do milho e farelo de soja serem os componentes básicos nas formulações para aves, alguns fatores antinutricionais presentes nos alimentos, principalmente no farelo de soja, fazem com que o aproveitamento dos nutrientes não seja completo. Como a utilização de enzimas nas dietas tinha como objetivo principal a redução da viscosidade da digesta no trato intestinal, pouco interesse foi direcionado ao uso de enzimas para rações à base de milho e farelo de soja, considerados grãos de baixa viscosidade, tendo pouca influência sobre esta. Porém, estudos de Noy \& Sklan (1995) mostraram que a digestibilidade do amido e da gordura foi relativamente baixa (aproximadamente $85 \%$ ), em relação às que se consideravam anteriormente (maior que 90\%), sugerindo que parte significativa do amido pode atingir o intestino grosso e sofrer degradação fermentativa. De acordo com Soto-Salanova et al. (1996), parece que a digestão do amido de milho (gordura/proteína) pode não ser tão completa em pintos como se pensava. Assim, para melhorar o valor nutritivo das dietas formuladas com cereais de baixa viscosidade, sugere-se, de acordo com Finnfeeds (1991), citado por Borges (1997), que o uso de complexos multienzimáticos seja mais efetivo, por atuar sobre uma série de polissacarídeos da parede celular dos grãos, levando a maior aproveitamento da dieta por parte das aves. Conforme relatado por Soto-Salanova et al. (1996), apesar de as aplicações de enzimas, para melhorar o valor nutritivo das dietas à base de milho e farelo de soja, estarem ainda em desenvolvimento, a utilização de um complexo multienzimático na dieta pode possibilitar redução nos níveis dietéticos dos nutrientes em até $6 \%$, sem comprometer o desempenho das aves, e apresentar boa relação custo/benefício.

Zanella et al. (1999) conduziram vários ensaios, nos quais os autores testaram o efeito da adição de um complexo enzimático (amilase, protease e xilanase) sobre a digestibilidade de vários nutrientes, por meio de várias metodologias, e o desempenho de frangos de corte recebendo dietas à base de milho e farelo de soja, suplementadas ou não com o complexo enzimático, reduzindo os níveis dietéticos de nutrientes, quando da adição de enzimas na dieta. Os autores encontraram melhora expressiva na digestibilidade dos nutrientes (proteína, amido, gordura e energia metabolizável), nas diferentes metodologias testadas (alimentação forçada, coleta total de excretas e digesta ileal), concluindo que a suplementação com enzimas permite reduzir o nível energético da dieta, sem afetar o desempenho das aves, e melhorar a digestibilidade de nutrientes. Por outro lado, Freitas et al. (1998) não encontraram efeito benéfico da suplementação enzimática em dietas à base de milho/farelo de soja para poedeiras. Assim, as pesquisas utilizando enzimas exógenas em rações avícolas, baseadas em milho e farelo de soja, são recentes e os resultados ainda contraditórios. Por outro lado, resultados de pesquisa utilizando óleo vegetal em rações de aves têm evidenciado uma melhoria na absorção de nutrientes, possivelmente porque este reduz o incremento calórico e influencia a taxa de passagem pelo trato gastrointestinal.

Dessa forma, o presente trabalho foi conduzido com os objetivos de verificar os efeitos da adição de óleo vegetal em rações à base de milho e farelo de soja, suplementadas ou não com um complexo enzimático, e possível efeito positivo e/ou associativo destes dois ingredientes, sobre a digestibilidade dos nutrientes das rações, bem como sobre o desempenho dos frangos de corte.

\section{Material e Métodos}

Dois ensaios foram conduzidos no Setor de Avicultura do Departamento de Zootecnia da Universidade Federal de Lavras - MG onde foram utilizados 960 pintos de um dia (ensaio 1), da linhagem AgRoss, não sexados, vacinados contra doença de Marek e Bouba Aviária, com peso médio inicial de 42,6 $\pm 0,8 \mathrm{~g}$. Ao final desta fase, 90 aves foram utilizadas em um ensaio de metabolismo (ensaio 2).

$\mathrm{O}$ ensaio 1 foi conduzido em esquema fatorial $4 \times 2$, em quatro repetições de 30 aves cada, sendo quatro níveis de óleo de soja $(0 ; 2,5 ; 5,0$ e 7,5\%), sem 
Tabela 1 - Composição dos ingredientes proteicos e energéticos utilizados nas rações ${ }^{1}$

Table 1 - Composition of the proteic and energy ingredients used in the diets

\begin{tabular}{|c|c|c|c|c|c|c|c|}
\hline $\begin{array}{l}\text { Ingredientes } \\
\text { Ingredients }\end{array}$ & $\begin{array}{c}\mathrm{EM}^{2} \\
M E \\
\mathrm{kcal} / \mathrm{kg}\end{array}$ & $\begin{array}{l}\mathrm{MS}^{3} \\
D M \\
(\%)\end{array}$ & $\begin{array}{c}\mathrm{PB}^{3} \\
C P \\
(\%)\end{array}$ & $\begin{array}{c}\mathrm{Ca}^{2} \\
\mathrm{Ca} \\
(\%)\end{array}$ & $\begin{array}{c}\mathrm{Pd}^{2} \\
A P \\
(\%)\end{array}$ & $\begin{array}{c}\mathrm{Met}+\mathrm{Cis}^{2} \\
M e t+C y s \\
(\%)\end{array}$ & $\begin{array}{c}\text { Lisina }^{2} \\
\text { Lysine } \\
(\%)\end{array}$ \\
\hline Milho & 3416 & 85,93 & 7,51 & 0,02 & 0,09 & 0,35 & 0,23 \\
\hline $\begin{array}{l}\text { Corn } \\
\text { Farelo de soja } \\
\text { Soybean meal }\end{array}$ & 2283 & 88,26 & 45,89 & 0,36 & 0,18 & 1,34 & 2,87 \\
\hline $\begin{array}{l}\text { Farelo de glúten } 60 \\
\text { Gluten meal } 60\end{array}$ & 3624 & 90,88 & 62,96 & 0,06 & 0,12 & 2,70 & 1,00 \\
\hline $\begin{array}{l}\text { Óleo de soja } \\
\text { Soybean oil }\end{array}$ & 8786 & 99,30 & - & - & - & - & - \\
\hline
\end{tabular}

Tabela 2 - Composição percentual das rações experimentais utilizadas

Table 2 - Percentual composition of the experimental diets used

\begin{tabular}{|c|c|c|c|c|}
\hline \multirow[t]{2}{*}{$\begin{array}{l}\text { Ingredientes } \\
\text { Ingredients }\end{array}$} & \multicolumn{4}{|c|}{$\begin{array}{c}\text { Nível de óleo (\%) } \\
\text { Oil level (\%) }\end{array}$} \\
\hline & 0,0 & 2,5 & 5,0 & 7,5 \\
\hline Complexo enzimático (Enzymatic complex) & $-\quad+$ & $-\quad+$ & -+ & -+ \\
\hline Milho (Corn) & 63,60 & 57,30 & 49,90 & 42,60 \\
\hline Farelo de soja (Soybean meal) & 24,00 & 33,92 & 35,40 & 36,75 \\
\hline Óleo de soja (Soybean oil) & - & 2,50 & 5,00 & 7,50 \\
\hline Farelo de glúten $60 \%$ (Gluten meal $60 \%$ ) & 7,20 & 1,00 & 1,00 & 1,00 \\
\hline Fosfato bicálcico (Dicalcium phosphate) & 1,84 & 1,82 & 1,84 & 1,86 \\
\hline Calcário calcítico (Limestone) & 1,24 & 1,20 & 1,14 & 1,20 \\
\hline $\operatorname{Sal}($ Salt $)$ & 0,40 & 0,40 & 0,40 & 0,40 \\
\hline Premix vitamínico $^{1}$ (Vitamin premix) $^{1}$ & 0,10 & 0,10 & 0,10 & 0,10 \\
\hline Premix mineral $^{2}$ (Mineral premix $^{2}$ & 0,10 & 0,10 & 0,10 & 0,10 \\
\hline Anticoccidiano (Anticoccidian) ${ }^{3}$ & 0,05 & 0,05 & 0,05 & 0,05 \\
\hline Antioxidante $(\text { Antioxidant })^{4}$ & - & 0,015 & 0,015 & 0,015 \\
\hline DL-metionina 99\% (DL-methionine 99\%) & 0,14 & 0,20 & 0,21 & 0,21 \\
\hline L-lisina $\mathrm{HCl}($ L-lysine $\mathrm{HCl})$ & 0,33 & 0,06 & 0,03 & 0,01 \\
\hline Inerte (Inert) & 1,00 & 1,335 & 4,815 & 8,205 \\
\hline \multicolumn{5}{|l|}{ Composição nutritiva (Nutritive composition) } \\
\hline Energia metab. $(\mathrm{kcal} / \mathrm{kg})^{5}$ (Metabolizable energy) & 2.981 & 2.987 & 2.987 & 2.989 \\
\hline Proteína bruta $(\%)^{5}$ (Crude protein) & 20,32 & 20,67 & 20,76 & 20,82 \\
\hline Cálcio (\%) (Calcium) & 1,04 & 0,99 & 1,00 & 1,03 \\
\hline $\mathrm{P}$ disponível (\%) (Available $P)$ & 0,44 & 0,45 & 0,45 & 0,45 \\
\hline Sódio (\%) (Sodium) & 0,20 & 0,20 & 0,20 & 0,20 \\
\hline Lisina $(\%)($ Lysine $)$ & 1,17 & 1,16 & 1,16 & 1,17 \\
\hline Met + Cis $(\%)$ (Methionine + cystine $)$ & 0,89 & 0,88 & 0,88 & 0,88 \\
\hline
\end{tabular}

ou com suplementação de um complexo enzimático comercial contendo $300 \mathrm{U}$ de xilanase, $400 \mathrm{U}$ de amilase e $4000 \mathrm{U}$ de protease/g do produto.

A composição química dos alimentos utilizados nas rações experimentais está apresentada na Tabela 1, sendo os valores de matéria seca (MS) e proteína bruta (PB) determinados no Laboratório de Nutrição Animal do DZO/UFLA e os demais obtidos de Rostagno et al. (1994). As rações foram isonutritivas (Tabela 2), constituídas principalmente de milho e

R. Bras. Zootec., v.32, n.4, p.909-917, 2003 


\section{Resultados e Discussão}

Experimento 1 - ensaio de desempenho

Não houve efeito da adição do complexo enzimático nem interação $(\mathrm{P}>0,05)$ dos níveis de óleo e suplementação enzimática nos períodos de 1 a 21 , bem como efeito residual $(\mathrm{P}>0,05)$ de 22 a 42 dias de idade, sobre o consumo de ração e ganho de peso (Tabelas 4 e 5). No entanto, à medida que os níveis de óleo foram aumentados nas rações, observou-se acréscimo linear $(\mathrm{P}<0,01)$ do consumo de ração $\left(\hat{Y}=971,25+10,285 X ; R^{2}=0,98\right)$ e do ganho de peso $\left(\hat{Y}=560,88+9,925 X ; R^{2}=0,83\right)$ no período de 1 a 21 dias de idade, efeito que se manteve na fase seguinte, mostrando haver efeito residual dos tratamentos aplicados na fase inicial de criação. Com relação à suplementação enzimática, os resultados encontrados estão de acordo com os trabalhos conduzidos por Marsman et al. (1995) e Pack \& Bedford (1997), que também não verificaram efeito significativo da adição de enzimas em dietas à base de milho e farelo de soja sobre o consumo de ração.

Entretanto, Garcia (1997) verificou maior consumo de ração em frangos de corte, tanto em dietas fareladas quanto peletizadas, à base de milho e soja, quando foram suplementadas com um complexo enzimático contendo as mesmas enzimas exógenas, porém em concentrações diferentes.

Constam na Tabela 6 os valores médios da conversão alimentar nas duas fases de criação. Observa-se

Tabela 4 - Consumo médio de ração, de acordo com os tratamentos

Table 4 - Mean intake of diet, according to treatments

\begin{tabular}{|c|c|c|}
\hline \multirow[t]{2}{*}{$\begin{array}{l}\text { Níveis de óleo (\%) } \\
\text { Oil levels }\end{array}$} & \multicolumn{2}{|c|}{$\begin{array}{c}\text { Consumo de ração (g/ave) } \\
\text { Feed intake (g/bird) }\end{array}$} \\
\hline & $\begin{array}{l}1 \text { a } 21 \text { dias }^{1} \\
1 \text { to } 21 \text { days }\end{array}$ & $\begin{array}{l}22 \text { a } 42 \text { dias }^{1} \\
22 \text { to } 42 \text { days }\end{array}$ \\
\hline 0 & 968 & 2611 \\
\hline 2,5 & 1003 & 2774 \\
\hline 5,0 & 1025 & 2826 \\
\hline 7,5 & 1047 & 2887 \\
\hline Média & 1011 & 2774 \\
\hline Mean & & \\
\hline $\begin{array}{l}\text { Sem enzima } \\
\text { Without enzvme }\end{array}$ & 1004 & 2800 \\
\hline $\begin{array}{l}\text { Com enzima } \\
\text { With enzvme }\end{array}$ & 1017 & 2747 \\
\hline CV (\%) & 5,57 & 4,81 \\
\hline
\end{tabular}

${ }^{1}$ Efeito linear $(P<0,01)$ (Linear effect $\left.P<.01\right)$.

R. Bras. Zootec., v.32, n.4, p.909-917, 2003 que não houve efeito significativo $(\mathrm{P}>0,05)$ da adição do complexo enzimático e da interação com os níveis de óleo utilizados nas rações nos dois períodos avaliados. Contudo, observa-se que a conversão alimentar no período de 1 a 21 dias de idade melhorou $(\mathrm{P}<0,01)$, quando o óleo foi adicionado nas rações, atingindo um platô no nível de 2,18\% de óleo (Figura 1), efeito não observado na fase seguinte, mostrando não haver efeito residual dos tratamentos aplicados na primeira fase sobre este parâmetro avaliado.

Tabela 5 - Ganho de peso médio dos frangos, de acordo com os tratamentos

Table 5 - Mean gain of broilers, according to treatments

\begin{tabular}{|c|c|c|}
\hline \multirow[t]{2}{*}{$\begin{array}{l}\text { Níveis de óleo (\%) } \\
\text { Oil levels }\end{array}$} & \multicolumn{2}{|c|}{$\begin{array}{c}\text { Ganho de peso }(\mathrm{g}) \\
\text { Weight gain }(\mathrm{g}) \\
\end{array}$} \\
\hline & $\begin{array}{l}1 \text { a } 21 \text { dias }^{1} \\
1 \text { to } 21 \text { days }^{1}\end{array}$ & $\begin{array}{l}22 \text { a } 42 \text { dias }^{1} \\
22 \text { to } 42 \text { days }{ }^{1}\end{array}$ \\
\hline 0 & 547 & 1342 \\
\hline 2,5 & 603 & 1377 \\
\hline 5,0 & 616 & 1468 \\
\hline 7,5 & 626 & 1466 \\
\hline Média & 598 & 1413 \\
\hline Mean & & \\
\hline $\begin{array}{l}\text { Sem enzima } \\
\text { Without enzyme }\end{array}$ & 593 & 1416 \\
\hline $\begin{array}{l}\text { Com enzima } \\
\text { With enzvme }\end{array}$ & 603 & 1410 \\
\hline CV $(\%)$ & 5,86 & 4,18 \\
\hline
\end{tabular}

${ }^{1}$ Efeito linear $(P<0,01)$ (Linear effect $\left.P<.01\right)$.

Tabela 6 - Conversão alimentar dos frangos, de acordo com os tratamentos

Table 6 - Feed conversion of broilers, according to the treatments

\begin{tabular}{|c|c|c|}
\hline \multirow[t]{2}{*}{$\begin{array}{l}\text { Níveis de óleo (\%) } \\
\text { Oil levels }\end{array}$} & \multicolumn{2}{|c|}{$\begin{array}{l}\text { Conversão alimentar } \\
\text { Feed conversion }\end{array}$} \\
\hline & $\begin{array}{l}1 \text { a } 21 \text { dias }^{1} \\
1 \text { to } 21 \text { days } 1\end{array}$ & $\begin{array}{l}22 \text { a } 42 \text { dias } 1 \\
22 \text { to } 42 \text { days } 1\end{array}$ \\
\hline 0 & 1,78 & 1,94 \\
\hline 2,5 & 1,66 & 2,01 \\
\hline 5,0 & 1,68 & 1,92 \\
\hline 7,5 & 1,67 & 1,95 \\
\hline Média & 1,70 & 1,96 \\
\hline Mean & & \\
\hline Sem enzima & 1,71 & 1,97 \\
\hline Without enzyme & & \\
\hline Com enzima & 1,69 & 1,95 \\
\hline With enzyme & & \\
\hline CV $(\%)$ & 4,32 & 4,65 \\
\hline
\end{tabular}

${ }^{1}$ Modelo LRP (Linear Response Plateau). 


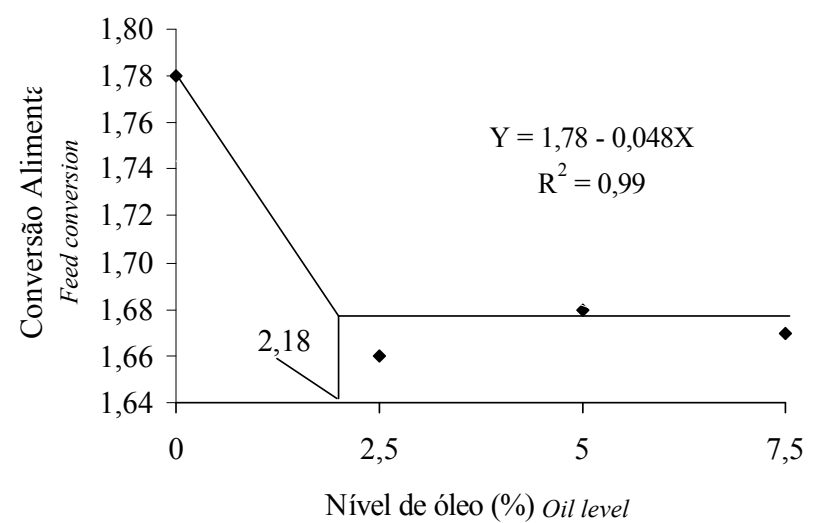

Figura 1 - Conversão alimentar no período de 1 a 21 dias de idade, segundo os níveis de óleo na ração.

Figure 1 - Feed conversion of 1 to 21 days of age, according to oil levels.

Os resultados de ganho de peso e conversão alimentar do presente experimento estão de acordo com aqueles obtidos por Rodrigues (2000) e Torres (1999), que avaliaram o desempenho das aves recebendo rações formuladas com adição de enzimas e não observaram efeito positivo da suplementação enzimática. Ao contrário dos autores citados, Zanella et al. (1999) observaram que a suplementação enzimática em dietas à base de milho e farelo de soja melhorou o ganho de peso e a conversão alimentar em 1,9 e $2,2 \%$, respectivamente. Garcia (1997) também verificou aumento de aproximadamente $5 \%$ no ganho de peso das aves, ao avaliar a suplementação enzimática em dietas à base de milho e farelo de soja.

A partir dos resultados de desempenho apresentados, observou-se que o uso de óleo nas rações proporciona melhores respostas para o ganho de peso, consumo de ração e conversão alimentar, estando estes resultados de acordo com os obtidos por Lana et al. (1995), Freitas et al. (1999a) e Rosa (1999). Observa-se ainda que, com exceção da conversão alimentar, houve efeito residual dos tratamentos aplicados na primeira fase onde, dos 22 a 42 dias, o desempenho das aves seguiu o mesmo comportamento da fase inicial, apesar de receberem uma ração comum.

Assim, pode-se pressupor que, como as rações foram isonutritivas, houve um efeito positivo da adição de óleo nas rações, possivelmente potencializado pelo aumento no consumo de ração e, conseqüentemente, de nutrientes. Por outro lado, a não constatação de interação dos níveis de óleo com enzimas mostra que, apesar de ambos serem descritos na literatura como benéficos na digestibilidade dos nutrientes e, conseqüentemente, na melhora do desempenho das aves, no presente trabalho não ficou evidenciada a ocorrência de um efeito associativo destes dois fatores.

\section{Experimento 2 - ensaio de metabolismo}

Não houve diferença significativa $(\mathrm{P}>0,05)$ nos valores de EMA e EMAn em relação ao níveis de óleo e uso do complexo enzimático nas rações, bem como interação $(\mathrm{P}>0,05)$ entre estes fatores (Tabela 7).

No entanto, Zanella et al. (1999), trabalhando com um complexo enzimático contendo as mesmas enzimas, porém em concentrações superiores às do presente trabalho, encontraram melhoras significativas nos valores da EMAn determinados com frangos intactos. Esses autores atribuíram tal melhora ao aumento na digestibilidade da gordura e do amido, principais constituintes bromatológicos que fornecem energia na dieta, proporcionados pela adição de enzimas. Porém, deve-se ressaltar que, por não conter a enzima lipase em sua composição, possivelmente a melhora na digestibilidade da gordura, destacada pelo referido autor, esteja associada ao efeito da enzima xilanase sobre os PNA, favorecendo a digestibilidade de outros nutrientes, no presente caso, da gordura.

Pelos resultados encontrados no presente trabalho, observa-se que o valor de EMAn aumentou em $2,3 \%(\mathrm{P}=0,066)$, quando se comparou à ração sem óleo e à média das rações em que houve a inclusão de óleo, mostrando que, possivelmente, houve efeito extra-calórico do óleo, uma vez que as rações foram formuladas para serem isoenergéticas.

A digestibilidade da matéria seca (CDMS) e a matéria seca excretada somente foram afetadas pelos níveis de óleo nas rações (Tabela 8), mostrando redução linear $(\mathrm{P}<0,01)$ dos CDMS $(\hat{\mathrm{Y}}=72,493$ $\left.0,955 \mathrm{X} ; \mathrm{R}^{2}=0,95\right)$ e aumento linear $(\mathrm{P}<0,01)$ da quantidade de matéria seca excretada $(\hat{\mathrm{Y}}=22,078+$ $\left.1,165 \mathrm{X} ; \mathrm{R}^{2}=0,95\right)$ quando os níveis de óleo foram aumentados. Os menores valores dos CDMS observados à medida que se aumentou os níveis de óleo na ração, talvez possam ser atribuídos ao maior teor de material inerte (caulim) adicionado às rações contendo óleo, para mantê-las isonutritivas. Assumindo-se que o caulim é indisponível para os animais, haverá maior teor de matéria seca nas excretas, o que se comprova pela maior quantidade de matéria seca excretada quando a dieta continha níveis mais altos 
Tabela 7 - Energia metabolizável aparente (EMA) e aparente corrigida pelo balanço de nitrogênio (EMAn) e seus respectivos desvios padrão, em rações com diferentes níveis de óleo sem ou com um complexo enzimático

Table 7 - Meteabolizable apparent (AME) and apparent corrected by the nitrogen balance (AMEn) and yours respectives standard deviation in diets with different oil levels without or with enzymatic complex

\begin{tabular}{lcc}
\hline $\begin{array}{l}\text { Níveis de óleo (\%) } \\
\text { Oil levels }\end{array}$ & $\begin{array}{c}\text { EMA (Kcal/kg de MS }) \\
\text { AME (Kcal/kg of DM) }\end{array}$ & $\begin{array}{c}\text { EMAn (Kcal/kg de MS })^{1} \\
\text { AMEn }(\text { Kcal/kg of DM) }\end{array}$ \\
\hline 0 & $3282 \pm 73$ & $3114 \pm 69^{\mathrm{b}}$ \\
2,5 & $3362 \pm 71$ & $3187 \pm 70^{\mathrm{a}}$ \\
5,0 & $3337 \pm 59$ & $3172 \pm 42^{\mathrm{a}}$ \\
7,5 & $3347 \pm 40$ & $3198 \pm 69^{\mathrm{a}}$ \\
Média (Mean) & $3332 \pm 66$ & $3168 \pm 68$ \\
Sem enzima (Withoutenzyme) & $3330 \pm 72$ & $3152 \pm 62$ \\
Com enzima (Withenzyme) & $3334 \pm 62$ & $3184 \pm 73$ \\
CV $(\%)$ & 2,00 & 2,01
\end{tabular}

$1 \mathrm{a}, \mathrm{b}(\mathrm{P}=0,066)$.

Tabela 8 - Coeficientes de digestibilidade da matéria seca (CDMS) e seus respectivos desvios-padrão, em rações com diferentes níveis de óleo sem ou com um complexo enzimático

Table 8 - Dry matter digestibility coefficients (CDMD) and respective standard deviation in diets with different oil levels without or with enzymatic complex

\begin{tabular}{lccc}
\hline $\begin{array}{l}\text { Níveis de óleo (\%) } \\
\text { Oil levels }\end{array}$ & $\begin{array}{c}\text { CDMS }(\%)^{1} \\
\text { DMDC }\end{array}$ & $\begin{array}{c}\text { MS excretada }^{1} \\
\text { Excreted DM }^{1}\end{array}$ & $\begin{array}{c}\text { CDMS corrigido }^{2} \\
\text { Corrected }^{\text {DMDC }}\end{array}$ \\
\hline 0 & $72,12 \pm 1,30$ & $22,13 \pm 2,24$ & $72,84 \pm 1,30$ \\
2,5 & $71,00 \pm 2,10$ & $24,30 \pm 2,83$ & $71,99 \pm 2,14$ \\
5,0 & $67,02 \pm 1,80$ & $29,12 \pm 3,24$ & $70,41 \pm 2,03$ \\
7,5 & $65,46 \pm 2,20$ & $30,24 \pm 1,39$ & $71,32 \pm 2,42$ \\
Média (Mean) & $68,90 \pm 3,30$ & $26,45 \pm 4,16$ & $71,64 \pm 2,12$ \\
Sem enzima (Without enzyme) & $68,79 \pm 4,08$ & $25,73 \pm 4,24$ & $71,52 \pm 2,30$ \\
Com enzima(With enzyme) & $69,00 \pm 3,05$ & $27,16 \pm 4,08$ & $71,76 \pm 1,99$ \\
CV (\%) (Coefficient of variation) & 2,91 & 9,32 & 2,97 \\
\hline
\end{tabular}

${ }^{1}$ Efeito linear $(\mathrm{P}<0,01)$ (Linear effect $\left.[P<.01]\right)$.

${ }^{2}$ Não-significativo $(P>0,10)$ (Not significant $[P>10]$ ).

de óleo e, conseqüentemente, de material inerte. Entretanto, ao se retirar da matéria seca excretada a quantidade de material inerte consumido (CDMS corrigido), não se observou efeito significativo $(\mathrm{P}>0,10)$ do aumento dos níveis de óleo na ração sobre os valores de digestibilidade da matéria seca. Tal observação permite concluir a necessidade de correção nos valores de digestibilidade da matéria seca pela quantidade de material inerte excretado, ao se trabalhar com adição de níveis mais elevados deste veículo na ração.

Por outro lado, Andreotti et al. (1999) observaram uma redução no tempo de trânsito da digesta quando aumentaram o nível de óleo nas rações. Assim, redução no tempo de trânsito da digesta também poderia levar à menor digestibilidade da matéria seca. Os referidos autores ainda destacaram que, embora a literatura cite a redução no tempo de trânsito como um dos efeitos extra-calóricos da adição de gorduras na dieta, em seu trabalho esta redução não ficou evidenciada.

Não houve efeito $(P>0,05)$ do uso de enzimas, bem como interação dos níveis de óleo e adição do complexo enzimático nas rações (Tabela 9). Estes resultados se assemelham aos observados por Bedford (1996), que também não encontrou diferenças significativas na digestibilidade do extrato etéreo, quando trabalhou com rações formuladas com farelo de soja e óleo, suplementadas ou não com enzimas. Assim como observado pelo referido autor, no presente trabalho este resultado era teoricamente esperado, uma vez que o complexo enzimático utilizado não continha a enzima lipase.

Pela Figura 2, observa-se que a digestibilidade do extrato etéreo apresentou efeito quadrático $(\mathrm{P}<0,01)$ em relação aos níveis de óleo da ração, com máxima 
digestibilidade no nível de 2,33\% de inclusão. Os resultados obtidos no presente trabalho se assemelham aos encontrados por Freitas et al. (1999) que, utilizando dietas contendo $0 \%$ e 3,0\% de óleo de soja para frangos de corte de 1 a 21 dias de idade, encontraram coeficientes de digestibilidade do extrato etéreo de aproximadamente $88 \%$, quando adicionaram óleo na ração, semelhante ao nível de $2,5 \%$ de óleo usado no presente experimento (87,5\%). De acordo com Sakomura (1996), o óleo adicionado às dietas com

Tabela 9 - Coeficientes de digestibilidade do extrato etéreo (CDEE) e seus respectivos desviospadrão, em rações com diferentes níveis de óleo com ou sem complexo enzimático

Table 9 - Ether extract digestibility coefficients (EEDC) and respectives standard deviation in diets with different oil levels without or with enzymatic complex

\begin{tabular}{lc}
\hline $\begin{array}{l}\text { Níveis de óleo (\%) } \\
\text { Oil levels }\end{array}$ & $\begin{array}{c}\text { CDEE }(\%)^{1} \\
\text { EEDC }\end{array}$ \\
\hline 0 & $86,00 \pm 1,90$ \\
2,5 & $87,50 \pm 3,30$ \\
5,0 & $86,00 \pm 4,00$ \\
7,5 & $77,00 \pm 3,00$ \\
Média (Mean) & $84,00 \pm 5,20$ \\
Sem enzima (Withoutenzyme) & $83,00 \pm 5,00$ \\
Com enzima (Withenzyme) & $85,00 \pm 5,50$ \\
CV (\%) & 3,53 \\
\hline
\end{tabular}

${ }^{1}$ Efeito quadrático $(P<0,01)$ (Quadratic effect $\left.P<.01\right)$.

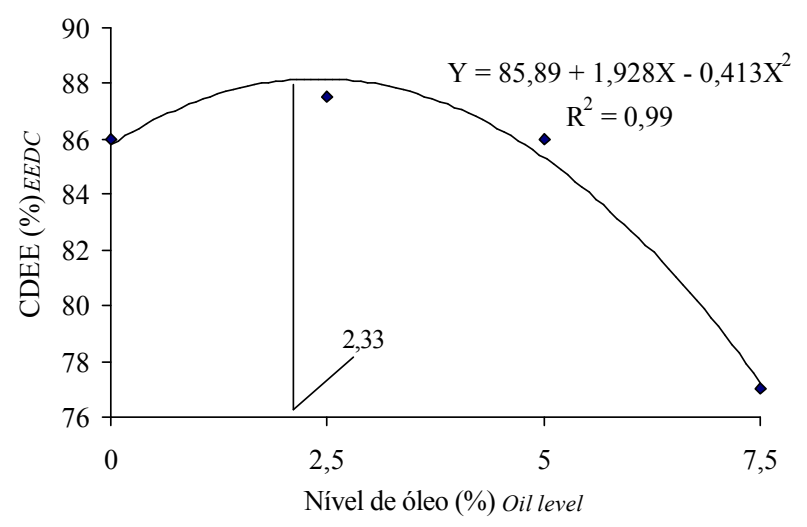

Figura 2 - Coeficientes de digestibilidade do extrato etéreo (CDEE) em função dos níveis de óleo na ração.

Figure 2 - Ether extract digestibility coefficients (EEDC) according to oil levels in the diet. farelo de soja, por estar na forma livre, também proporciona melhores condições para o aproveitamento da gordura, além de promover uma digestão e absorção mais completa da ração. Esse melhor aproveitamento das gorduras no presente experimento foi determinado com o nível de $2,33 \%$ de óleo, podendo-se concluir que a partir desse nível as aves não conseguem aproveitar de maneira racional as gorduras.

\section{Conclusões}

A inclusão de óleo na ração melhorou o desempenho das aves e a conversão alimentar permaneceu constante a partir de $2,18 \%$ de inclusão. O nível de $2,33 \%$ de óleo permitiu máxima digestibilidade do extrato etéreo e a EMAn melhorou em 2,3\% com a inclusão de óleo nas rações. A adição de enzimas na ração não melhorou o desempenho das aves.

\section{Literatura Citada}

ANDREOTTI, M.O.; JUNQUEIRA, O.M.; BARBOSA, M.J.B. et al. Influência da fonte energética no tempo de trânsito de rações para frangos de corte. In: INTERNATIONAL CONFERENCE ON AGROPOLES AND AGRO-INDUSTRIAL TECHNOLOGICAL PARKS, 1999, Barretos. Anais... Barretos: AGROTEC'99, 1999. p.412-415.

ASSOCIATION OF OFFICIAL ANALYTICAL CHEMIST AOAC. Official methods of analysis: agricultural chemicals, contaminants and drogs. 15.ed. Washington: Association of official analytical chemists, 1990. v.1, 684p.

BEDFORD, M.R.; MORGAN, A.J. The use of enzymes in poultry diets. World's Poultry Science Journal, v.52, n.1, p.61-68, 1996.

BORGES, F.M.O. Utilização de enzimas em dietas avícolas. Cadernos Técnicos da EV da UFMG, n.20, p.5-30, 1997.

FRANCO, S.G. Programas de alimentação e fontes de óleo para frangos de corte. Jaboticabal: Universidade Estadual Paulista, 1992. 118p. (Tese - Doutorado em Produção Animal) - Universidade Estadual Paulista, 1998.

FREITAS, B.C.F.; BAIÃO, N.C.; NUNES, I.J. et al. Digestibilidad de la grasa en las primeras semanas de vida del pollo de carne. In: CONGRESSO LATINO AMERICANO DE AVICUlTURA, 16., 1999, Lima. Anais... Lima, 1999a. p.356-359.

FREITAS, B.C.F.; BAIÃO, N.C.; NUNES, I.J. et al. Efecto del aceite de soya sobre la performance inicial de los pollos de carne. In: CONGRESSO LATINO AMERICANO DE AVICULTURA, 16., 1999, Lima. Anais... Lima: 1999b. p.360-363.

FREITAS, E.R.; FUENTES, M.F.F.; ESPÍNDOLA, G.B. Suplementação enzimática das dietas à base de milho/soja para poedeiras comerciais. In: REUNIÃO ANUAL DA SOCIEDADE BRASILEIRA DE ZOOTECNIA, 35, 1998, Botucatu. Anais... Botucatu: Sociedade Brasileira de Zootecnia, p.318-320. 1998.

GARCIA, O. Enzimas: recentes contribuições para a sua aplicação em nutrição animal. In: ENCONTRO DE NUTRIÇÃO ANIMAL, 3., 1997, São Paulo. Anais... São Paulo: 1997. p.1-9.

R. Bras. Zootec., v.32, n.4, p.909-917, 2003 
LANA, G.R.Q.; SILVA, D.J.; SILVA, M.A. et al. Desempenho comparativo de marcas comerciais e de cruzamentos de diferentes linhagens de frangos de corte produzidos na UFV, em diferentes níveis de energia. 1. Consumo de ração, ganho de peso e conversão alimentar. Revista da Sociedade Brasileira de Zootecnia, v.24, n.5, p.759-767, 1995.

MARSMAN, G.J.P.; GRUPPEN, H.; Van der POEL, A.F.B. et al. The effect of shear forces and addition of a mixture of a protease and hemicelulase on chemical, physical and physiological parameters during extrusion of soybean meal. Animal Feed Science and Technology, v.56, n.1/2, p.21-35, 1995.

MATEOS, G.G.; SELL, J.L. Influence of fat and carbohydrate source on rate of food passage of semipurified diets for laying hens. Poultry Science, v.60, p.2114-2119, 1981.

NOY, Y., SKLAN, D. Digestion and absorption in the young chick. Poultry Science, v.74, n.2, p.366-373, 1995.

NUTRIENT REQUIREMENTS COUNCIL. Nutrient requirements of poultry. 9.ed. Washington, D.C.: National Academy Press, 1994. 155p.

PACK, M.; BEDFORD, M. Feed enzymes for corn-soybean broiler diets. A new concept to improve nutritional value and economics. World's Poultry Science Journal, v.53, n.1, p.87-93, 1997.

RODRIGUES, P.B. Digestibilidade de nutrientes e valores energéticos de alguns alimentos para aves. Viçosa, MG: Universidade Federal de Viçosa, 2000. 204p. (Tese de Doutorado) - Universidade Federal de Viçosa, 2000.

ROSA, F.C. Teor de ácidos graxos poliinsaturados ômega-3 no peito e na coxa de frangos de corte alimentados com rações contendo 3 fontes de óleo. Lavras: Universidade Federal de Lavras, 1999. 94p. Dissertação (Mestrado em Zootecnia) - Universidade Federal de Lavras, 1999.

Rostagno, H.S.; SILVA, D.J.; COSTA, P.M.A. et al. Composição de alimentos e exigências nutricionais de aves e suínos (Tabelas Brasileiras). Viçosa, MG: Universidade Federal de Viçosa, 1994. 59p.
SAKOMURA, N.K. Estudo do valor nutricional das sojas integrais processadas e de sua utilização na alimentação de frangos e poedeiras. Jaboticabal: Universidade Estadual de São Paulo, 1996. 178p. Tese (Livre Docência em Avicultura) - Universidade Estadual de São Paulo, 1996.

SOTO-SALANOVA, M.F.; GARCIA, O.; GRAHAM, H. et al. Uso de enzimas em dietas de milho e soja para frangos de corte. In: CONFERÊNCIA APINCO 96 DE CIÊNCIA E TECNOLOGIA AVÍCOLAS, 1996, Curitiba. Anais... Campinas: FACTA, 1996. p.71-76.

TEIXEIRA, Z.S. Utilização do óleo de soja na alimentação de frangos de corte. Viçosa, MG: Universidade Federal de Viçosa, 1974. 81p. (Dissertação de Mestrado) - Universidade Federal de Viçosa, 1974.

TORRES, D.M. Suplementação de rações para frangos de corte com protease, amilase e xilanase. Lavras: Universidade Federal de Lavras, 1999. 80p. Dissertação (Mestrado em Zootecnia) - Universidade Federal de Lavras, 1999.

UNIVERSIDADE FEDERAL DE VIÇOSA - UFV. Manual de utilização do programa SAEG (Sistema para análises estatísticas e genéticas). Viçosa, MG: Universidade Federal de Viçosa, 1992. 59p.

ZANELLA, I.; SAKOMURA, N.K.; SILVERSIDES, F.G. et al. Effect of enzyme supplementation of broiler diets based on corn and soybeans. Poultry Science, v.78, n.4, p.561-568, 1999. 